\title{
Editorial
}

\section{Syringomyelia in Cervical Spondylosis: A Rare Sequel}

\author{
H. S. Bhatoe ${ }^{1}$ \\ ${ }^{1}$ Department of Neurosciences, Max Super Specialty Hospital, \\ Patparganj, New Delhi, India
}

Indian J Neurosurg 2016;5:1-2.

Neurological involvement in cervical spondylosis usually implies radiculopathy or myelopathy. Cervical spondylotic myelopathy is the commonest cause of myelopathy in the geriatric age group, ${ }^{1}$ and often an accompaniment in adult patients manifesting central cord syndrome and spinal cord injury without radiographic abnormality. Myelopathy is the result of three factors that often overlap: mechanical factors, dynamic-repeated microtrauma, and ischemia of spinal cord microcirculation. ${ }^{2}$ Age-related mechanical changes include hypertrophy of the ligamentum flavum, formation of osteophytic bars, degenerative disc prolapse, all of them contributing to a narrowing of the spinal canal. Degenerative kyphosis and subluxation often aggravates the existing compression on the spinal cord. Flexion-extension movements of the spinal cord places additional, dynamic stretch on the cord that is compressed. The stretch occurs across the osteophytic bar during flexion, and on extension, the buckled hypertrophic ligament flavum compresses the cord. Ischemia due to compromise of microcirculation and venous congestion, leading to focal demyelination. ${ }^{3}$

Syringomyelia is an extremely rare sequel of chronic cervical cord compression due to spondylotic process, and manifests as accelerated myelopathy (-Fig. 1). Pathogenesis of syringomyelia is uncertain. Al-Mefty et $\mathrm{al}^{4}$ postulated occurrence of myelomalacia due to chronic compression of the cord, followed by phagocytosis, leading to a formation of the cavity that extends further. However, Kimura et $\mathrm{al}^{5}$ disagreed with this hypothesis, and postulated that following compression of the cord, there is slosh effect cranially and caudally, leading to an extension of the syrinx. It is thus likely that focal cord cavitation due to compression and ischemia occurs due to periventricular fluid egress into the cord, the underlying mechanism being pulsatile stresses in the presence of pressure differentials across the compressive region. It is

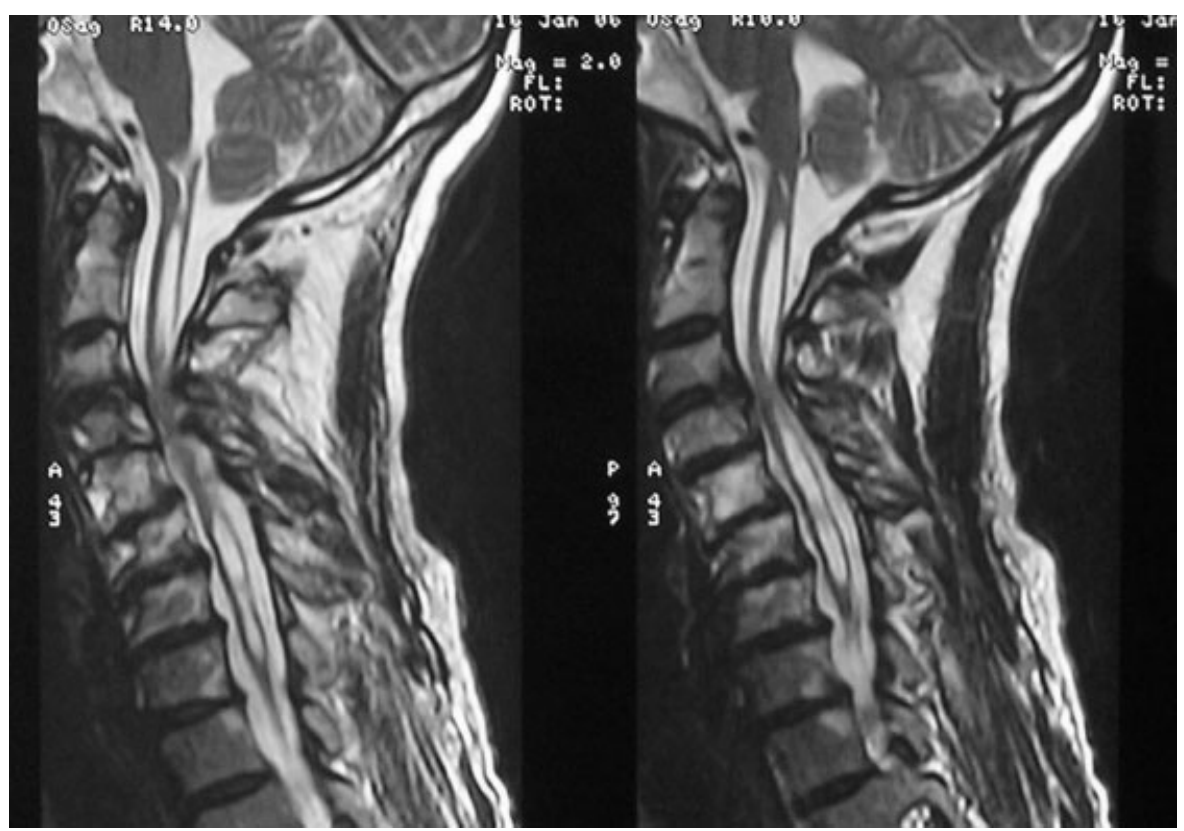

Fig. 1 MRI of cervical spine (T2-weighted, sagittal) showing cervical spondylosis with cord compression and syringomyelia. MRI, magnetic resonance imaging.

Address for correspondence H. S. Bhatoe, MCh, Department of Neurosciences, Max Super Specialty Hospital, Patparganj, 108A IP Extension, New Delhi 110092, India

(e-mail: hsbhatoe@gmail.com).
C 2016 Neurological Surgeons' Society of India

DOI http://dx.doi.org/ 10.1055/s-0036-1579750. ISSN 2277-954X. 
likely that these changes occur along with focal myelomalacia, and do not show signs of recovery after decompression. Ball and Little ${ }^{6}$ reported a patient with Chiari I formation, cervical disc prolapse, and syringomyelia. Syringomyelia resolved after surgery for cervical disc prolapse. Rebai et $\mathrm{al}^{7}$ reported a 70-year-old patient with cervical spondylotic myelopathy with syringomyelia, which had extended cranially to form syringobulbia.

Evaluation of a patient with syringomyelia in the setting of cervical spondylosis includes exclusion of the craniovertebral junction anomaly, posterior fossa or intraspinal tumors, or a history of trauma to the spine. The extent of syringomyelia is variable, and there are no clear-cut guidelines on its management. Kimura et $\mathrm{al}^{5}$ obtained a resolution of syrinx after anterior decompression, while Kaar et $\mathrm{al}^{8}$ showed reduction of syrinx with a posterior decompression. While there may not be any improvement in spasticity and hypertonia, there is however an improvement in sensory symptoms in the form of relief of pain and paresthesiae. More studies are needed to see the evolution of syringomyelia in the setting of cervical spondylotic myelopathy.

\section{References}

1 Young WF. Cervical spondylotic myelopathy: a common cause of spinal cord dysfunction in older persons. Am Fam Physician 2000;62(5):1064-1070, 1073

2 Baron EM, Young WF. Cervical spondylotic myelopathy: a brief review of its pathophysiology, clinical course, and diagnosis. Neurosurgery 2007;60(1, Suppl 1):S35-S41

3 Ogino H, Tada K, Okada K, et al. Canal diameter, anteroposterior compression ratio, and spondylotic myelopathy of the cervical spine. Spine 1983;8(1):1-15

4 Al-Mefty O, Harkey LH, Middleton TH, Smith RR, Fox JL. Myelopathic cervical spondylotic lesions demonstrated by magnetic resonance imaging. J Neurosurg 1988;68(2):217-222

5 Kimura R, Park YS, Nakase H, Sakaki T. Syringomyelia caused by cervical spondylosis. Acta Neurochir (Wien) 2004;146(2): 175-178

6 Ball JR, Little NS. Chiari malformation, cervical disc prolapse and syringomyelia-always think twice. J Clin Neurosci 2008;15(4): 474-476

7 Rebai R, Boudawara MZ, Ben Yahia M, Mhiri C, Ben Mansour H. Syringomyelobulbia associated with cervical spondylosis. Pathophysiology and therapeutic implications [in French]. Neurochirurgie 2002;48(2-3 Pt 1):120-123

8 Kaar GF, N'Dow JM, Bashir SH. Cervical spondylotic myelopathy with syringomyelia. Br J Neurosurg 1996;10(4):413-415 